March $2006 \bullet \underline{\text { Volume } 100} \bullet \underline{\text { Number } 3}$

\title{
The Psychosocial Experiences of a Student with Low Vision
}

\author{
Anne L. George and Cheryll Duquette
}

Abstract: This article presents an in-depth case study of the psychosocial experiences of Eric, a student with low vision, who is enjoying social success in his neighborhood school. It explores the factors that contribute to Eric's social successes at school and in the community and presents a model for inclusion.

The majority of students who are visually impaired (that is, are blind or have low vision) in Canada and the United States are educated within inclusive classrooms in their neighborhood schools, rather than in residential schools for students with visual impairment (American Foundation for the Blind, n.d.). Yet, research in several Western countries has revealed that many of these students are lonely and isolated from their sighted peers. They have fewer friends, fewer opportunities to socialize, and fewer occasions to develop their interpersonal skills than do students who are sighted (Huurre \& Aro, 2000; Huurre, Komulainen, \& Aro, 1999; Kef, 2002; Kekelis \& Sacks, 1992; MacCuspie, 1992; McGaha \& Farran, 2001; Rosenblum, 1998; Schneekloth, 1989). Despite earnest attempts to include children who are visually impaired in regular classrooms, many of them continue to be disadvantaged socially and emotionally (Corn \& Koenig, 1996).

To date, few studies (MacCuspie, 1992, 1996; Sacks, Wolffe, \& Tierney, 1998) have sought to understand the social and 
emotional experiences of young students with low vision who are considered to be relatively well integrated and socially accepted by their sighted peers, although there have been a small number of studies on adolescents (see, for example, Huurre et al, 1999; Rosenblum, 1998). Rosenblum, in particular, called for such inquiries, recognizing the "need to obtain additional information on the social aspects of visual impairments" at the elementary level and that identifying visually impaired students "who are interacting successfully will enable researchers to isolate the skills and strategies these children use and to develop interventions to aid those who are unsuccessful in this area" (p. 595).

The purpose of the case study that is presented in this article was to consider the social and psychological experiences of students with visual impairments by examining the psychosocial development of Eric (a pseudonym), a sixth-grade student with low vision. Merriam (1998) suggested that a case study of this nature, in which the focus is on the individual, is best described as a psychological case study. She further differentiated the psychological case study by characterizing it as a means to investigate human behavior on an individual basis or within a program, event, or process. In our case study, we examined Eric's personal experiences, as well as the perspectives of significant individuals in his life, that contributed to his overall emotional well-being and success in the classroom.

\section{Review of the literature}

Research on the social development of students who are visually impaired has revealed that many students are disadvantaged socially when compared to their sighted peers (Kekelis \& Sacks, 1992; McGaha \& Farran, 2001; Rogow, 1999). The lack of visual input, perceptions of the lack of attractiveness, and decreased levels of physical activity and perceived competence further place these students at risk of being isolated from their sighted peers 
(Frame, 2000; Gold, 2002; Hopkins, Gaeta, Thomas, \& Hill, 1987; Kekelis, 1992; Shapiro, Moffett, Lieberman, \& Dummer, 2005; Van Hasselt, 1983).

In school settings, students who are visually impaired use different media to access the curriculum, including large print, audio materials, and braille, which may lead children who are sighted to develop false notions about them. These incorrect perceptions include the belief that they (the sighted children) are more intelligent than are those who are visually impaired because they may have superior fluency when reading and writing (Kekelis, 1992; MacCuspie, 1992). Students with low vision may also be considered to be at a greater risk than those who are blind for deficient social knowledge. In a noteworthy study of social and practical knowledge (Corn \& Bishop, 1984), students with low vision scored significantly lower (mean results at the 25th percentile) than did those who were blind (mean results at the 50th percentile) on the Practical Knowledge Quotient, probably because the students with low vision were not afforded the same level of verbal support (explanations) as were those who were blind. Therefore, for many reasons, students with low vision may become socially isolated from their sighted peers, even in inclusive classrooms.

Because of the variability that exists among students with low vision, such as the nature of the impairment and age of onset, the presence of other conditions or syndromes, learning aptitude, and type of reading medium, research results that are generalizable have been difficult to achieve. While the results of most studies have shown a lack of development of social skills and peer rejection among students with low vision, further research is needed to provide teachers and researchers with a better understanding of the factors that contribute to these students' successful inclusion. 


\section{Method}

\section{Research questions and case-study design}

The research questions that guided this study were as follows:

1. does a preadolescent boy with low vision perceive his successes in the school and community, and how do these perceptions differ from those of other significant individuals in his life?

2. What elements contribute to the boy's level of social success?

A case-study design, based on Merriam's (1998) paradigm, was used to reveal -Eric's emotional peaks and valleys. (Merriam's paradigm focuses on the individual as a means of evaluating and interpreting some aspect of human behavior.) The unique qualities of the case study are rooted in its emic stance; it is more interested in highlighting personal constructs or narratives that are created by the participants. Furthermore, case study research is more "concrete and sensory" (Merriam, 1998, p. 32) because of its reliance on participant and reader interpretation. In this case study, a constructivist approach, one that strives to understand the meaning that individuals have constructed, was adopted. These "human constructions" (Guba \& Lincoln, 1994, p. 108) are context--dependent; they are narratives that belong to a particular setting or viewpoint, and the analysis attempts to provide an indepth understanding of the interaction between these contexts.

\section{Participants}

The principal participant in this single-case study was Eric, an 11year-old sixth-grade student with low vision from a rural school in Ontario, Canada. Eric was a strong student academically, was athletically inclined, and was good-natured. His diagnosis of 
oculocutaneous albinism and nystagmus rendered his visual acuity as 20/100 (OU) with correction. Although fair skinned with blonde hair, Eric did not have the signature white hair and pink skin that are often associated with albinism. In the classroom, he was afforded the use of a desktop computer with a scanner and screen-reading software and was further accommodated through the use of audio books, large-print texts, and preferential seating. He had received the support of an itinerant teacher of students who are visually impaired since he entered school, with the frequency of visits varying from weekly to biweekly to monthly. Additional participants included Eric's current and previous year's teachers, neither of whom had previously taught a student with a visual impairment, yet both of whom were veteran teachers (with 18 or more years of teaching experience). The final participant was Eric's mother, who is best described as a caring and supportive parent. Although Eric's father was not formally interviewed during the study, his presence was strong in Eric's life.

\section{Data collection}

Merriam (1998) identified three primary sources of data that are commonly associated with the case study: interviews, observations, and documents. She also maintained that the data to be considered should be closely linked with the researcher's theoretical orientation, the purpose of the study, and the choice of participants. For this case study, qualitative data were gathered from multiple sources of information over a two-month period. Data collection included 45-minute individual audiotaped semistructured interviews with Eric, two of his teachers, and his mother. Three hours of classroom observations were also completed and included field notes. A review of Eric's school file provided additional insights into his social abilities. The data were transcribed from the field notes and audiotaped interviews after each observation period or interview session, and they were further subjected to member checks to ensure that the participants' 
true voices were captured. Pseu-donyms were used throughout the study to ensure anonymity.

\section{Data analysis}

The psychological case study is characterized by first-person narratives (Merriam, 1998). In this study, the data analysis adopted a sociolinguistic tone, in that it attempted to underscore the social relationships within the narrative, and relied on personal memories to create the structure. Data collection and analysis occurred simultaneously, and personal insights guided the questions to elicit a vivid description of key events and themes. The data were analyzed inductively and were divided into meaningful units, coded, and organized into the categories of sports, friendships, challenges, social successes, and promoting social development (Miles \& Huberman, 1994). Themes emerged from these categories, and the findings were organized around them. As the categories emerged, inferences and assertions about the case were made, linking the conceptual elements of the case to create a holistic narrative (Stake, 1995). The use of field notes and documents enhanced the descriptions that were constructed. The comments have been edited slightly for grammar and syntax; however, the original meanings have been maintained. The use of multiple perspectives, detailed description, constant comparison of data, triangulation, and member checks facilitated the creation of a sound, persuasive narrative (Merriam, 1998; Stake, 1995).

\section{Findings}

The individual interviews provided a rich description of many key events and interactions that contributed to Eric's psychosocial development. The analysis of the data yielded four recurring themes: (1) sports, (2) friendships and popularity, (3) the role of the teacher, and (4) the role of the parent. The ensuing discussion provides a detailed examination of how one child with low vision 
matured socially and the important role that sports and his parents played in his life. It also highlights Eric's positive and negative experiences at school and in the community, as witnessed by individual participants.

\section{Sports}

The role of sports was a central recurring theme in all the interviews, and it is within this context that the majority of the analysis took place. Eric was an athletic boy and played a variety of sports, both at school and in his community. When defining himself, he inevitably invoked his success with sports, disclosing that "when our team wins tournaments, ... when I get a medal in wrestling," is what truly made him happy. In spite of his obvious visual limitations, Eric consistently tried his best to succeed in all athletic endeavors. His peers, however, sometimes became impatient with him and sometimes excluded him because he was unable to play competitively during a game. Carol, his former teacher, indicated that "when it came time to choose teams, he wasn't chosen as quickly; Eric would be one of the ones near the end to be chosen." However, Eric remained motivated and continued to play intramural sports at school, as well as sports that were organized in the community.

\section{Friendships and popularity}

Popularity is a complex social phenomenon, and many boys at this age associate it with prowess in sports (both teachers reported that boys who were athletically accomplished had a much higher social standing than did boys who were not). The teachers also reported that Eric was well liked and included by his peers, except during gym class; hence, his social status among his peers seemed to be context-dependent. For example, Eric enjoyed a high level of popularity in the classroom, where his teachers reported that he was, from their perspective, a social equal with his classmates. 
Eric's computer became a tool for connecting with many classmates, since he was proficient in its use and was always willing to share his expertise. Notetaking, in particular, became a cooperative activity, in which a sighted classmate would dictate notes to Eric, who would print out two copies, one for each of them. Therefore, the data suggested that Eric enjoyed a measure of popularity among his sighted peers in the regular classroom, at least when academics were involved.

Eric himself perceived his closest friends to be those who "understand why I wear glasses and who I can help" and those who "play hockey or wrestling." Again, he seemed to be describing two distinct groups of children in his life, namely, those with whom he could connect on an emotional level of mutual understanding and those with whom he shared sporting camaraderie. His mother considered this duality:

... He thinks that he needs to be friends with a certain group of kids, and I wonder if he's missing out on the ones who really do enjoy his company because to Eric, they're not the ones that he wants to be friends with. To me, he wants to be friends with the ones who are athletic. I know who he thinks are his friends, but I don't know if they are his friends. Because to be a best friend has to be something that's reciprocated, and I don't know if that's necessarily the case.

When asked about his closest friends, Eric named two individuals, both academically strong students who did not excel in sports, suggesting that when he really thought about his friends, Eric valued the emotional connection that he had with his "academic friends," who perhaps understood and accepted his visual limitations. However, as his mother implied, he appeared to long for stronger connections with the high-status athletic boys, thereby gaining increased recognition and acceptance by association.

Eric was able to develop lasting friendships at a summer camp in Ontario for children who are visually impaired. He reflected on 
his camp experiences this way:

It's fun. (long pause) Basically everyone knows what it's like to be visually impaired or blind. . . I'm happy there. We can go swimming, canoeing, bisketing [floating on an inner tube towed by a motor boat], or just play in our cabins. ... They have challenges for us.

Eric was able to play in an environment where, visually, he was on an equal footing with his peers. These happy experiences allowed him to develop relationships with children who faced similar challenges.

Eric was given numerous opportunities to develop friendships within a range of social settings, yet with various degrees of success. Although he gained personal satisfaction from participating in athletic activities, it is not clear whether he was truly accepted by his sighted peers as an equal within these nonacademic social settings. On the other hand, his experiences at camp allowed him to connect with other visually impaired children without having to worry about their reactions to his disability. Taken together, the variety of friendships in Eric's social network challenged the assumption that visual impairment is synonymous with psychosocial deficits. Although his impairment made Eric a less desirable teammate during physical education classes and other sports activities, his peers in all other areas of his life accepted him.

\section{Teachers}

The extent of Eric's social successes varied according to the individual perspectives of the participants. At school, Eric's teachers considered him to be well liked and respected by his sighted classmates. Moreover, they had high expectations for all their students and did not appear to treat Eric differently from the other students. Although at the beginning of the year, they may have doubted their ability to teach a student with a visual 
impairment, these fears quickly dissipated as they became more comfortable with Eric's learning accommodations.

Eric's teachers embraced an inclusive philosophy, understood his visual limitations, and saw beyond his disability to capitalize on his learning strengths. They also encouraged socialization with his peers through the use of cooperative learning strategies. Diane, his present teacher, used both homogeneous and heterogeneous groupings to ensure that all her students worked with each other. She also used literature circles and chose Eric as a library helper to maximize opportunities for social interactions and leadership roles. Once again, Eric's teachers clearly understood and took full advantage of the additional benefits afforded by Eric's computer. For instance, a chosen peer dictated material that was on the chalkboard while Eric typed the information on his computer (two copies were printed for their use). Eric's scanning and screen-reading software enabled him to assist other auditory learners or unsuccessful readers in the class. These examples demonstrate that the teachers often viewed Eric's -social-emotional and physical development to be just as important as his academic pursuits and planned their lessons accordingly by ensuring that Eric was able to work with a variety of peers during many of the lessons.

\section{Parents}

Eric was fortunate to live in a stable home environment with two loving and caring parents who supported his development. Eric's mother, in particular, was interested and involved in Eric's day-today experiences and worked closely with his teachers to encourage positive home-school relations. Both parents had high academic and social expectations for their son. Furthermore, they had the financial means to enroll him in numerous activities outside school (such as hockey, wrestling, camp, and skiing) that supported his physical and social development. Eric's mother 
admitted that she was sometimes overly emotional and sensitive to the challenges that her son faced and saw herself as constantly having to advocate and think ahead on behalf of her son. She stated, "I'm always looking out for Eric."

Eric's mother perceived his psychosocial development less positively than did his teachers, identifying numerous occasions in which Eric was socially isolated from his sighted peers. The hockey rink was mentioned repeatedly as an environment in which he was unable to participate fully in the spontaneous and unorganized off-ice games that arose (such as hide and seek, horseplay, and chasing). Eric's limited vision further complicated positive communication at the rink. As his mother noted:

... At the rink, Eric's not the one to say "Hello!" first because he doesn't know who's there. He picks one spot that he sits in within the changing room, and he's not going up to any of the kids to sit and talk because he doesn't know who's there! So, are the kids thinking, "Oh, he doesn't like me; he doesn't want to sit with me"?

Eric's mother was acutely aware of missed opportunities and struggled with how far she should be pushing her son to participate in extracurricular activities. It appeared that she found the right balance, since her son was passionate about sports.

Eric's parents thought that they did not deny their children much and that their son should be given the same opportunities as children without disabilities. Yet getting Eric to try new things was often challenging for them. His mother clarified this point:

I would say that it would be a struggle to get him to try everything. It's hard for Eric. He doesn't readily go and try new things .... . He doesn't want to embarrass himself. He doesn't want anybody laughing at him. You have to push him, and once he realizes that "yes, he can" or "it's OK, I really don't need to see this much," then he's fine, but we have a lot of temper tantrums to get him to try something new. We get dramatics. 
Eric's parents strongly encouraged him to try new things and, by doing so, promoted Eric's sense of accomplishment and selfworth. They were the driving force behind Eric's successes in the classroom and in his extracurricular activities.

\section{Discussion}

The findings of this study suggest that the psychosocial development of students with low vision may not always be compromised by limitations of or perceptions of visual impairment and that these students may not, inevitably, have difficulty with peer relations. Eric perceived himself as a socially accepted member of his class who was treated as an equal by teachers and peers. He attributed his success in the classroom to a variety of personal attributes, including his helpful nature, his academic standing, his athleticism, and his ability to educate his sighted peers and the staff about his specific needs (self-advocacy skills).

Eric's parents considered their son to be well integrated into his school, yet felt that they continually had to advocate on his behalf. The first month of school was particularly stressful as Eric's mother worked to develop good rapport with new classroom teachers to ensure that any learning issues would be addressed in a timely and positive manner. Eric's parents realized the importance of providing ample opportunities for socialization and, in essence, forced Eric to be active in the sighted world.

Eric's teachers also considered Eric to be successfully integrated into his classroom environment. Although they did not include him as one of the most popular group of boys in their respective classes, both teachers did agree that he was a well-liked, valuable, and contributing class member. Furthermore, both teachers named physical education as an area in which Eric was less popular among his sighted peers. However, the academic subjects 
afforded him more opportunities to share his intellectual and personal strengths, thereby increasing his social status among his classmates.

\section{Model for successful inclusion}

In this study, Eric achieved social competence as a result of the interactions within a variety of systems in his life. The model for successful inclusion presented in Figure 1 demonstrates the interrelation of the various systems in Eric's life. Several aspects of this model have been discussed by Sacks, Kekelis, and Gaylord--Ross (1992). The framework suggests that many factors come into play to achieve positive outcomes. Each system must be solid in its own right, yet must allow for a harmonious interplay between each of the other systems. In Eric's case, the parental and familial system interacted with the teacherinstructional system, and together they influenced, with various degrees of intensity (indicated by the solid and broken arrows), the personal and peer systems. These various systems are discussed next in relation to Eric.

\section{The parental and familial system}

Research has linked a family's cognitive and emotional level of functioning with social competence (Moos, 1991), and it is this system that has the greatest influence on the personal system. Fortunately, Eric's parental and familial system was characterized by a stable home life with consistently high expectations. His parents lovingly encouraged Eric, often under protest, to participate in the nondisabled world. Opportunities to develop friendships, through athletic activities in the community and attendance at a summer camp with other children with visual impairment, also fostered his psychosocial development. Last, advocacy efforts by his parents ensured that Eric's needs were met in a variety of settings. 


\section{The teacher-instructional system}

In Eric's case, the teacher-instructional system set the stage for both positive and negative interactions (such as computer breakdowns and instructional materials not being prepared in large print) within the school setting. Both his former and his current teacher had adopted an inclusive philosophy and sought professional knowledge and resources to enhance their teaching abilities. In addition, they implemented numerous strategies, such as cooperative learning and orchestrated leadership roles for Eric within the classroom, to promote interpersonal development. Eric's teachers also had high expectations for his academic and personal growth. Finally, advocacy efforts by the teachers on behalf of Eric facilitated a mutual understanding and respect for Eric's unique learning abilities among his sighted peers.

\section{The personal system}

Eric's personal system was influenced by numerous individual factors, such as Eric's temperament, personality, and self-efficacy; intellectual profile; academic and personal achievements (such as in athletics); and the nature and severity of his disability. Eric appeared to take his visual impairment in stride and exuded a positive self-image. He was a strong student academically and remained motivated to achieve because he experienced repeated successes both in the classroom and in his athletic activities.

\section{The peer system}

The peer system involves the variety of personal interactions that a student has on any given day with his or her peers. Although Eric seemed to long for a stronger relationship with the popular athletic boys, he likely was considered just an acquaintance to them. Within the classroom, actual friendships were cultivated with the "academic" children through the use of Eric's computer. 
Further positive friendships developed at camp, where Eric was immersed in recreational activities with like-minded youngsters.

On the whole, and in spite of all the physical and social barriers that are associated with low vision, Eric remained a confident and self-assured young man who was liked and respected by his classmates. The narratives of the study's participants suggested that he was excluded not because of certain undesirable personality traits or deficits in social skills, but because of missed visual cues and physical limitations related to his vision.

\section{Limitations}

One significant shortcoming of this study was the limited amount of time devoted to data collection and analysis. Given more time, additional data might have been collected from classmates and peers, other family members, and other staff members. This study was further limited in its small sample of one young, white male student in a rural setting who came from a middle-class, twoparent family. Although the study did not draw on multiple participants who were demographically representative of Canadian society, the choice of participants was by no means atypical.

\section{I mplications}

Although many students who are visually impaired have considerable deficits in social skills and few intimate friendships, not all do (Huure et al., 1999; Rosenblum, 1998). Professionals who work in the field of visual impairment may hold false assumptions about the social and emotional abilities of students with low vision. The findings of this study suggest that several relevant factors contributed to Eric's healthy psychosocial development, including his home and classroom environment; his sighted peers' knowledge of his visual impairment and 
appreciation for the adverse learning conditions it may create; his motivation and past successes in a variety of endeavors (academics and athletics); the time spent with other students with similar disabilities; and, perhaps most important, his parents' encouragement and support. In Eric's case, all partners worked cooperatively to create a supportive environment, which fostered Eric's development of appropriate skills and strategies.

Low vision and blindness are low-incidence exceptionalities that frequently result in fewer opportunities for interaction with other children with similar disabilities, particularly if the children with visual impairment are integrated into neighborhood schools. Teachers of students who are visually impaired should consider organizing events, such as field trips, special lunches, or student exchanges, to give students who are visually impaired the opportunity to spend time with other students who share comparable experiences. Parents may enroll their youngsters in after-school activities to promote social inclusion and social competence, especially in rural areas where children may not play with each other after school. Teachers of students who are visually impaired, special educators, and classroom teachers should continue to apply teaching strategies that promote positive social outcomes (such as cooperative learning and literature circles). Furthermore, physical education teachers may include games and activities in which students with low vision can compete on an equal footing. Finally, school boards are encouraged to adopt the suggestions of the Association for Education and Rehabilitation of the Blind and Visually Impaired's (AER) Division 16 "Position Paper on Caseload Analysis" (n.d.) to provide teachers of students who are visually impaired with sufficient time to promote social and emotional learning within inclusive classroom settings.

\section{Suggestions for future research}


Most of the research on the social experiences of students with visual impairment has adopted a deficit view of social dysfunction and may be limited in its sample (that is, it may focus on adolescents). The findings of this study invite researchers to challenge this paradigm by further investigating the heterogeneity that exists among this population. Future work may extend this study and those of others (such as Sacks et al, 1998) to include a larger sample of preadolescent children, thereby improving the generalizability of the results. A comparison of teachers' perceptions of psychosocial acceptance and peer acceptance would also be worthwhile. In addition, gender differences and the nature of social interactions with the student with low vision may be examined. Further research may also include a long-term study of the psychosocial development of students who are visually impaired, with a particular emphasis on the role of recreational activities. Finally, the framework presented in this study needs to be applied to other children with visual impairments (or other disabilities) to explain their social success or failure.

\section{References}

AER Division 16. (n.d.). Position paper of AER's Division 16, itinerant personnel (Goal 4 of the National Agenda). Caseload analysis: A critical component of quality services for students with visual impairments [Online]. Available: http://aerbvi.org/ downloads/8/0/POSITION\%20PAPER\%20OF\% 20AERDivision\%2016\%20caseloads.doc

American Foundation for the Blind. (n.d.). Educating students with visual impairments for inclusion in society [Online]. Available: http://www.afb.org/Section.asp?

SectionID=44\&TopicID

$=189 \&$ DocumentID $=1344$ 
Corn A. L., \& Bishop, V. E. (1984). Acquisition of practical knowledge by blind and visually impaired students in grades 812. Journal of Visual Impairment \& Blindness, 78, 352-356.

Corn, A. L., \& Koenig, A. J. (1996). Foundations of low vision: Clinical and functional perspectives. New York: AFB Press.

Frame, M. J. (2000). The relationship between visual impairment and gestures. Journal of Visual Impairment \& Blindness, 94, 155-171.

Gold, M. E. (2002). The effects of the physical features associated with albinism on the self-esteem of African American youths. Journal of Visual Impairment \& Blindness, 96, 133-142.

Guba, E. G., \& Lincoln, Y. S. (1994). Competing paradigms in qualitative research. In N. K. Denzin \& Y. S. Lincoln (Eds.), Handbook of qualitative research (pp. 105-117). Thousand Oaks, CA: Sage.

Hopkins, W. G., Gaeta, H., Thomas, A. C., \& Hill, P. M. N. (1987). Physical fitness of blind and sighted children. European Journal of Applied Physiology and Occupational Physiology, 56 (1), 69-73.

Huurre, T., \& Aro, H. (2000). The psychosocial well-being of Finnish adolescents with visual impairments versus those with chronic conditions and those with no disabilities. Journal of Visual Impairment \& Blindness, 94, 625-637.

Huurre, T., Komulainen, E., \& Aro, H. (1999). Social support and self-esteem among adolescents with visual impairments. Journal of Visual Impairment \& Blindness, 93, 26-37.

Kef, S. (2002). Psychosocial adjustment and the meaning of social support for visually impaired adolescents. Journal of 
Visual Impairment \& Blindness, 96, 22-37.

Kekelis, L. S. (1992). Peer interactions in childhood: The impact of visual impairment. In S. Z. Sacks, L. S. Kekelis, \& R. J. Gaylord-Ross (Eds.), Development of social skills by blind and visually impaired students (pp. 13-35). New York: American Foundation for the Blind.

Kekelis, L. S., \& Sacks, S. Z. (1992). The effects of visual impairment on children's social interactions in regular education programs. In S. Z. Sacks, L. S. Kekelis, \& R. J. Gaylord-Ross (Eds.), Development of social skills by blind and visually impaired students (pp. 59-82). New York: American Foundation for the Blind.

MacCuspie, P. A. (1992). The social acceptance and interaction of visually impaired children in integrated settings. In S. Z. Sacks, L. S. Kekelis, \& R. J. Gaylord-Ross (Eds.), Development of social skills by blind and visually impaired students (pp. 83102). New York: American Foundation for the Blind.

MacCuspie, P. A. (1996). Promoting acceptance of children with disabilities: From tolerance to inclusion. Halifax, Nova Scotia: Atlantic Provinces Special Education Authority.

McGaha, C. G., \& Farran, D. C. (2001). Interactions in an inclusive classroom: The effects of visual status and setting. Journal of Visual Impairment \& Blindness, 95, 80-94.

Merriam, S. B. (1998). Qualitative research and case study applications in education. San Francisco: Jossey-Bass.

Miles, M. B., \& Huberman, M. (1994). Qualitative data analysis: A sourcebook of new methods (2nd ed.). Newbury Park, CA: Sage. 
Moos, R. H. (1991). Connections between school, work and family settings. In B. J. Fraser \& H. J. Walberg (Eds.), Educational environments: Evaluation, antecedents and consequences (pp. 29-53). Oxford, England: Pergamon Press.

Rogow, S. M. (1999). The impact of visual impairments on psychosocial development. In V. L. Schwean \& D. H. Saklofske (Eds.), Handbook of psychosocial characteristics of exceptional children (pp. 523-539). New York: Kluwer Academic.

Rosenblum, L. P. (1998). Best friendships of adolescents with visual impairments: A descriptive study. Journal of Visual Impairment \& Blindness, 92, 593-608.

Sacks, S. Z., Kekelis, L. S., \& Gaylord-Ross, R. J. (Eds.). (1992). Development of social skills by blind and visually impaired students. New York: American Foundation for the Blind.

Sacks, S. Z., Wolffe, K. E., \& Tierney, D. (1998). Lifestyles of students with visual impairments: Preliminary studies of social networks. Exceptional Children, 64, 463-478.

Schneekloth, L. H. (1989). Play environments for visually impaired children. Journal of Visual Impairment \& Blindness, 83, 196-201.

Shapiro, D. R., Moffett, A., Lieberman, L., \& Dummer, G. M. (2005). Perceived competence of children with visual impairments. Journal of Visual Impairment \& Blindness, 99, 1525.

Stake, R. (1995). The art of case study research. Thousand Oaks, CA: Sage. 
Van Hasselt, V. B. (1983). Social adaptation in the blind.

Clinical Psychology Review, 3, 87-102.

Anne L. George, M.A., candidate psycho-educational resource staff and teacher of students with visual impairments, Special Education Department, Renfrew County District School Board, 480 Mary Street, Pembroke, ON K8A 5W9, Canada; e-mail: <georgea@fc.renfrew.edu.on.ca>.Cheryll Duquette, Ph.D., associate professor, Faculty of Education, University of Ottawa, 145 Jean-Jacques Lussier Street, Ottawa, ON K1N 6N5, Canada; e-mail: <cduquette@uottawa.ca>.

$\because$ : Download braille-ready file

$\square$ Download ASCII text file

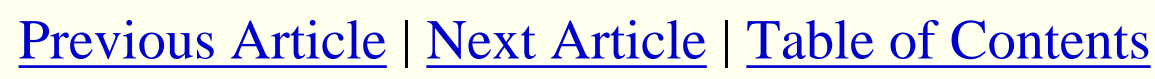

JVIB, Copyright (C) 2006 American Foundation for the Blind. All rights reserved.

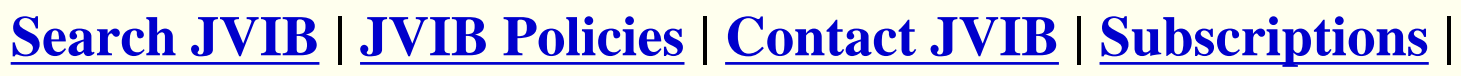 JVIB Home}

If you would like to give us feedback, please contact us at jvib@afb.net. 


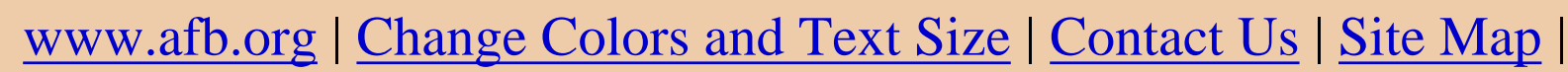
Site Search $\square$ Go

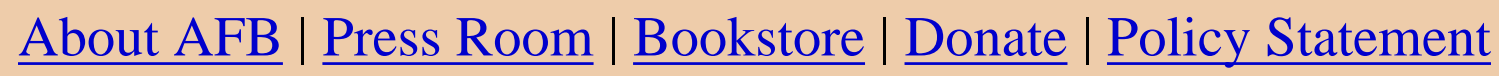

Please direct your comments and suggestions to afbinfo@afb.net Copyright (c) 2006 American Foundation for the Blind. All rights reserved. 